\title{
A QUALIDADE PERCEBIDA PELO PACIENTE ATRAVÉS DOS SERVIÇOS DA HOTELARIA HOSPITALAR: um estudo sobre a hospitalidade na área da saúde
}

\section{THE QUALITY PERCEIVED BY PATIENT THROUGH HOSPITAL HOTEL SERVICES: study on the hospitality in the health support service}

\author{
Rúbia Gisele Tramontin Mascarenhas (MASCARENHAS, R. G. T.) ${ }^{*} \mathrm{e}$ \\ Janaina Therezinha de Souza (SOUZA, J. T.) ${ }^{* *}$
}

\begin{abstract}
RESUMO - A multidisciplinaridade da área do turismo tem possibilitado novas áreas de atuação do profissional, incluindo o setor de saúde. Na hotelaria hospitalar os conceitos da hotelaria tradicional são adaptados às necessidades das instituições de saúde. A estruturação da hotelaria hospitalar tem sido aplicada em hospitais, tanto públicos como privados, com crescimento expressivo nas instituições de saúde. Este trabalho objetivou identificar os fatores responsáveis por agregar a qualidade percebida pelo paciente no ambiente hospitalar por meio dos serviços coordenados pela hotelaria. Para tanto, foi analisada a funcionalidade dos serviços de hotelaria hospitalar de hospital universitário, utilizado como estudo de caso. Para a composição dos resultados foram utilizados os formulários do serviço de Atendimento ao Cliente (SAC), preenchidos por pacientes e acompanhantes que receberam os serviços no hospital em estudo. A partir dessa análise pôde-se comprovar a importância da hotelaria hospitalar estar estruturada com objetivo de oferecer serviços de qualidade aos pacientes, adaptando os serviços hoteleiros à realidade e às particularidades de uma instituição de saúde. Comprovou-se que os serviços de apoio estavam oferecendo conforto e bem estar, auxiliando pacientes e familiares, inferindo na expectativa inicial do paciente de hospital público e superando suas expectativas.
\end{abstract}

Palavras-chave: Hotelaria Hospitalar; Qualidade; Serviço de Atendimento ao Cliente SAC; Hospitalidade; Hospital Universitário.

ABSTRACT - The multidisciplinarity in tourism has enabled new areas of professional practice, including the health sector. In the Hospital-Hotel Services the concepts of traditional hotels are adapted to the needs of health institutions. The structure of hospital hotel services has been applied in both public and private hospitals, with significant growth in health institutions. This paper aimed to identify the responsible factors for adding the quality perceived by the patient in the hospital through the services coordinated by hotel services. For this propose it was analyzed the functionality of the hospital hotel services in a university hospital, which was used as a case study. In order

\footnotetext{
* Formação: Graduação em Turismo e Hotelaria pela Universidade do Vale do Itajaí (UNIVALI - SC), Especialização em Gestão de Pessoas em Organizações pela Universidade do Oeste do Paraná (UNIOESTE - PR), Mestrado em Ciências Sociais Aplicadas pela Universidade Estadual de Ponta Grossa (UEPG) e Doutorado em Geografia pela Universidade Federal do Paraná (UFPR). Atividade profissional: Professora do Departamento de Turismo da Universidade Estadual de Ponta Grossa - UEPG. Endereço físico para correspondência: Praça Santos Andrade, n. 1, Bloco A. Departamento de Turismo. CEP 84030-900 - Ponta Grossa - Paraná (Brasil). E-mail: rubiatin@uepg.br ** Formação: Graduação em Turismo pela Universidade Estadual de Ponta Grossa (UEPG). E-mail:
jana_menon@hotmail.com
} 
to compose the results it was used the forms of Customer Support Service (Serviço de Atendimento ao Consumidor - SAC), completed by the patients and their companions who received those services at the hospital studied. From this analysis it can be proved the importance of Hospital-Hotel Services being structured in order to offer services with quality to the patients, adapting the hotel services to reality and to the particularities of a health institution. It was shown that the support services were offering comfort and well-being, helping patients and families, inferring the in the initial expectation of the public hospital patient and exceeding their expectations.

Key words: Hospital-Hotel Services; Quality; Customer Support Service - SAC; Hospitality, University Hospital. 


\section{INTRODUÇÃO}

O turismo, na sua totalidade é uma atividade multidisciplinar e interdisciplinar, onde estão envolvidos diversos setores que o permeiam de maneira direta ou indireta, sendo serviços oferecidos que visam primordialmente atender os desejos e necessidades dos turistas. Devido a ampla abrangência do setor que compõe o turismo é importante considerar suas especificidades e campos de atuação do profissional. O profissional em turismo encontra campos de atuação tradicionais, alguns consolidados no mercado, mas também surgem novas possibilidades aos profissionais do setor, dentre elas a hotelaria hospitalar tem apresentado grandes oportunidades no mercado brasileiro. Sendo aqui apresentado um estudo de caso em hospital universitário público no interior do Estado do Paraná.

A hospitalidade traz a oportunidade de adequação dos mecanismos e serviços desenvolvidos em hotéis. A hotelaria hospitalar apresenta conceitos e publicações desta nova área de estudo e atuação, adaptando a hotelaria tradicional à realidade hospitalar. Esse mercado já dispõe da atuação inclusive por profissionais de turismo e hotelaria.

A Hotelaria Hospitalar é um setor relativamente novo dentro das instituições de saúde. No Brasil o termo "Hotelaria Hospitalar" é recente, pois há pouco mais de uma década começou a surgir a necessidade de implantação do setor específico de hotelaria, sendo responsável pela gestão e qualidade em prestações dos serviços de apoio hospitalar, tais como: portaria, lavanderia e rouparia, nutrição e dietética e limpeza, entre outros departamentos. Portanto, a Hotelaria Hospitalar é a reunião desses serviços de apoio, onde segundo Boeger (2008, p. 24) "associados aos serviços específicos, oferecem aos clientes internos e externos conforto, segurança e bem estar durante seu período de internação".

Dessa forma, a busca constante pela qualidade em prestação de serviços, tanto como estrutura e organização, como é o caso dos hotéis, quanto no atendimento prestado e a hospitalidade oferecida ao hóspede, devem ser objetivos imprescindíveis da empresa. Oferecer produtos e serviços de qualidade tem sido fundamental na diferenciação de empresas, onde por meio de mudanças e adequações buscam atender as exigências de seus clientes que procuram vivenciar novas experiências a cada viagem e em cada hospedagem. Com isso, consumidores estão se tornando cada vez mais 
exigentes em função dessa constante transformação no mercado e pela ampliação de bens e serviços que lhe são oferecidos (BOEGER, 2011), ocorrendo, nesse caso, um ciclo entre mercado e consumidores.

Tem-se como problema do presente trabalho identificar quais os serviços da hotelaria clássica encontravam-se inseridos nas instituições de saúde e como esses serviços proporcionavam melhor conforto, comodidade e bem estar ao paciente, na percepção do atendimento de qualidade. Para responder a problemática proposta, objetivou-se com esse trabalho: identificar de que maneira a hotelaria hospitalar poderia agregar qualidade aos serviços ofertados e analisar a partir de resultados de pesquisa de satisfação, a percepção dos pacientes diante dos serviços desenvolvidos pela hotelaria hospitalar.

Como prática de pesquisa, foi realizado um estudo de caso do Hospital Universitário Regional dos Campos Gerais (HURCG) da cidade de Ponta Grossa (Paraná, Brasil), o qual estava possuindo o setor de hotelaria hospitalar na sua administração. O hospital em estudo localiza-se na região sul do Brasil no município de Ponta Grossa, estado do Paraná, é um hospital universitário, totalmente público.

Inaugurado em março de 2010, o hospital possui um total de 180 leitos de internamentos, 30 leitos na Unidade de Terapia Intensiva e 8 leitos na UTI Neonatal. Segundo dados da Gestão de Pessoas do hospital, durante as pesquisas, a instituição possuía um total de 562 servidores nos mais diversos setores, tanto de assistência quanto administrativos e de apoio geral.

Desde a sua inauguração implantou o Setor de Hotelaria Hospitalar, o qual mantinha sob sua supervisão os serviços de nutrição e dietética via oral, rouparia, limpeza, manutenção predial, portaria, segurança patrimonial e apoio geral do hospital.

Por meio de uma pesquisa qualitativa descritiva, foram analisados os serviços operacionalizados pela Seção de Hotelaria Hospitalar e a funcionalidade desses departamentos na estrutura do hospital. Foi realizada uma análise dos resultados do SAC (Serviço de Atendimento ao Cliente), aplicados aos pacientes da clínica médica e clínica cirúrgica que utilizavam os serviços da hotelaria hospitalar, durante a internação. No hospital em questão o SAC estava aplicado nos setores de ambulatório, imagem, clínica médica e cirúrgica. Sendo analisados nesta pesquisa os setores com maior 
relacionamento com a hotelaria em função de características específicas no internamento de pacientes.

Com relação a questão temporal foram analisadas as pesquisas de satisfação dos meses de outubro de 2012 a junho de 2013 desses dois setores. Apesar do início do SAC ter ocorrido em outubro de 2011, desde o mês de outubro de 2012 a aplicação das pesquisas de satisfação foi realizada separadamente nas duas clínicas, distinguindo clínica médica de clínica cirúrgica, portanto, este foi o critério do período de análise.

Os formulários utilizados apresentavam questões avaliativas sobre a equipe de cozinha, limpeza e rouparia, com perguntas sobre o atendimento, educação e simpatia dos funcionários, pontualidade, sabor e aparência da refeição, limpeza das instalações e dos enxovais, entre outros. As questões estavam sendo aplicadas pelo Setor de Serviço Social e respondidas pelos pacientes durante o período de internamento. Ainda realizouse entrevistas diretas com o serviço social sendo possível identificar a metodologia do SAC aplicado no hospital. Durante o período analisado foram realizadas 65 pesquisas de satisfação na clínica médica e 377 pesquisas na clínica cirúrgica. Essa diferença está em relação aos serviços oferecidos, de modo geral, podendo-se dizer que leitos cirúrgicos possuem um giro maior em função da complexidade dos procedimentos.

Desta maneira, apresenta-se a abrangência do setor de turismo considerando em suas especificidades a hospitalidade, o atendimento e a qualidade percebida pelo cliente através da hotelaria hospitalar.

\section{HOTELARIA HOSPITALAR}

Analisando o contexto histórico entre instituições de turismo, hotelaria e de saúde, aponta-se que a relação entre hotelaria, hospitais e a hospitalidade é muito estreita. As palavras possuem a mesma origem, do latim hospitale, que significa o ato de hospedar, de acolher com satisfação e prazer (BOEGER, 2008).

Devido às particularidades de hospedarias e hospitais, muitas foram as razões de separar esses dois meios de hospedagem, distinguindo pacientes de hóspedes. Porém, atualmente se fundem, surgindo dentro de algumas instituições de saúde um setor responsável, dentre outras especificidades, pelo bem estar de pacientes e 
acompanhantes, enquanto os mesmos permanecem dentro do hospital, setor denominado como Hotelaria Hospitalar.

A Hotelaria Hospitalar se caracteriza pelo conjunto de serviços da hotelaria convencional adaptados às particularidades do ambiente hospitalar. Quanto a isso, Boeger (2008, p. 11) descreve que deve-se "respeitar o escopo da hotelaria ao cabível no negócio de saúde, adaptando os conceitos hoteleiros da hotelaria convencional à realidade hospitalar", já que os dois empreendimentos possuem em suas realidades, especificidades e objetivos diferentes, afirmando com isso que os "hospitais hospedam pessoas comprovadamente doentes, enquanto os hotéis hospedam pessoas supostamente sadias" (TARABOULSI, 2009, p. 32).

No entanto, a implementação dos serviços de hotelaria nos hospitais pode ser entendida apoiando-se em Di Dio, Rettondini e Souza (2005, p. 805), como uma estratégia de diferenciação, onde valoriza o serviço oferecido e assim é percebido pelos clientes e concorrentes como um processo voltado à qualidade e melhoria contínua.

Para Boeger, (2008) um dos principais fatores que levou essa tendência de implantação da hotelaria nas instituições de saúde é o fato dos próprios pacientes estarem mais exigentes, visto que ao procurar por um tratamento médico, eles não esperam receber apenas o tratamento devido, mas a segurança, o conforto e um atendimento de qualidade dentro do hospital. Ainda:

\footnotetext{
Atualmente, os clientes de saúde sabem que a tecnologia e o conhecimento técnico e científico estão ao alcance de todas as instituições de saúde, entretanto, eles procuram e exigem atendimento hospitalar humanizado: respeito, carinho, dedicação e serviços de hotelaria em que o sorriso faz-se presente de uma forma sincera e permanente (TARABOULSI, 2009, p. 3).
}

Para autores como Boeger (2008; 2009; 2011) e Taraboulsi (2009) no passado os pacientes procuravam apenas por um atendimento médico. Em outro momento, os pacientes buscavam além de bons médicos e benefícios no atendimento, uma tecnologia de ponta, instalações e equipamentos novos. $\mathrm{Na}$ atualidade, estes pacientes, denominados como "clientes de saúde" (BOEGER, 2009), sabem que além dos mecanismos oferecidos pela área assistencial nos hospitais, lhes é de direito também, atendimentos cada vez melhores e mais humanizados, por parte de toda equipe, pois o cliente "quando entra pelo hospital, espera um atendimento que vem ao encontro de suas expectativas ou as excede" (TARABOULSI, 2009, p. 5). 
As atribuições da hospitalidade e a humanização prestada em atendimentos estão intimamente ligadas com os serviços coordenados pela Hotelaria Hospitalar, sendo esses serviços responsáveis por contribuir para o bem estar, conforto e segurança do paciente. Boeger (2011, p. 61) salienta que "a acolhida do hóspede está relacionada à aceitação deste no território hospitalar e ao compromisso de oferecer a ele o que se tem de melhor".

Além desse aspecto, os hospitais estão criando espaços diferenciados, com inovações arquitetônicas, pinturas nas paredes e objetos de decoração. Percebe-se com isso, que um agradável ambiente hospitalar, juntamente com serviços oferecidos por pessoas qualificadas e um bom atendimento, tanto da equipe assistencial quanto pela equipe de apoio, são fundamentais durante o processo de recuperação do paciente oferecendo-lhe além do tratamento devido, uma melhor comodidade durante esse período em que permanece na instituição.

Essas mudanças não estão direcionadas somente aos hospitais particulares do Brasil, mas inclusive em hospitais da rede pública. Embora muitos hospitais públicos enfrentem dificuldades adicionais, muitas vezes por falta de recursos, alguns deles conseguem com competência e criatividade, desenvolver um trabalho tão bom quanto de alguns hospitais privados (BOEGER, 2008).

No cenário nacional estudos do hospital Israelita Albert Eisntein (WADA, 2011) apresentam que em 2006 aproximadamente 5.600 profissionais atuavam das diversas áreas no ambiente hospitalar. O estudo já apontava uma previsão de crescimento para 2014, contando com aproximadamente 11.700, profissionais entre médicos, equipe assistencial e de apoio. Destes os cargos de hotelaria representaram $13 \%$ desse quantitativo referenciando-se a análise realizada em 2011.

Com isso, a hotelaria presente nos hospitais, como setor destinado a coordenar os serviços de apoio, mesmo não estando diretamente ligados à cura e recuperação de pacientes, tem como responsabilidade desenvolver suas funções de forma que possa contribuir para um maior bem estar e comodidade desse paciente enquanto ele estiver na instituição, visando a humanização e agregando a hospitalidade desenvolvida na área hoteleira, dentro da esfera hospitalar. 


\section{QUALIDADE NA PRESTAÇÃO DE SERVIÇOS HOSPITALARES}

O hóspede do hotel ou o paciente do hospital devem ser vistos como o foco na prestação de serviços. Para que conquistem seus clientes os empreendimentos precisam estipular diferenciais que agregam valor à oferta de seus serviços (PINTO, 2006). Portanto, esse diferencial deve partir da gestão da empresa, buscando ofertar serviços de qualidade que satisfaçam a sua demanda.

Qualidade pode ser caracterizada como o "conjunto das propriedades e características de um produto, processo ou serviço que lhe fornecem capacidade de satisfazer às necessidades explícitas e implícitas" (TARABOULSI, 2009, p. 10). O autor ainda traz como exemplo de qualidade no ambiente hospitalar o serviço médico assistencial destinado à cura do paciente, com o apoio dos serviços da hotelaria hospitalar, tornando-se uma inovação da instituição.

Ainda, as necessidades explícitas são as expressas formalmente e "se tratam de questões objetivas [...] as necessidades implícitas, por sua vez, dizem respeito às expectativas ou aos desejos dos clientes" (RODRIGUES; LEAL; HARGREAVES, 1997, p. 15). Como exemplo prático, o paciente, que explicitamente precisa de um tratamento médico eficaz no combate a uma doença. A necessidade implícita se caracteriza como a perspectiva e a percepção do paciente diante do serviço hospitalar por ele recebido, sendo essa segunda necessidade de ordem subjetiva.

Pode-se afirmar que a qualidade é atingida quando o retorno do cliente é positivo, durante a prestação desse serviço. Na hotelaria, essa ocorrência de prestação de serviços é denominada por Castelli (2006) como Momento da Verdade. Para Branco; Ribeiro e Tinoco (2010), a percepção da qualidade é formada em cada momento em que o cliente está em contato com o serviço desenvolvido, bem como com o prestador desse serviço. É nesse momento que o cliente "ao entrar em contato com a realidade da organização, tem oportunidade de formar um conceito da empresa e dimensionar a qualidade dos serviços por ela prestados" (RODRIGUES; LEAL; HARGREAVES, 1997, p. 24).

A partir dessas abordagens, nota-se a importância da empresa investir na qualificação de seus funcionários, uma vez que a prestação de serviços os tem como responsáveis pelo contato com o cliente e devem fazê-lo de forma eficiente. 
Cada pessoa da organização é vista como parte integrante de um ou mais processos que correspondem sempre à melhoria da qualidade. Tal melhoria, no entanto, envolve a análise de resultados do desempenho atual, a discussão de meios para aprimorar o desempenho e a partir disso, a implantação de novos métodos (ZANOVELLO, 2011). É o planejamento para um melhor desempenho dos serviços, visando sempre à melhoria contínua.

Além disso, deve haver a preocupação em atender as necessidades do cliente de modo que venham atingir as expectativas por ele previamente definidas, resultando em sua satisfação mediante serviço recebido. Por ser uma questão extremamente subjetiva, as expectativas, a satisfação e até mesmo a qualidade percebida pelo cliente diante do serviço prestado variam de cliente para cliente, levando em consideração os diversos fatores sociais e culturais inerentes.

Moller (2002) aponta que um produto ou serviço com a mesma qualidade podem ser percebidos de formas distintas por pessoas de um mesmo país, porém com cultura, educação, formação e idades diferentes. Ainda, a qualidade pode ser percebida pela mesma pessoa de formas diversas, porém em épocas diferentes. Ou seja, em muitos casos, o julgamento pessoal do consumidor acerca da boa ou má qualidade do serviço ou produto também irá depender do estado emocional e da situação em que ele se encontra.

Com relação a qualidade nos serviços de saúde, ressalta-se que o paciente encontra-se muitas vezes em situações debilitadas e estado emocional bastante fragilizado. Assim sendo:

[...] os hospitais estão tentando deixar de lado a imagem clássica de hospital levando para suas instituições mudanças e serviços que minimizam o impacto desses momentos difíceis, transformando a estada no ambiente hospitalar mais agradável, afinal, as pessoas nunca terão prazer de estar no hospital, mas o desconforto pode ser minimizado (TABABOULSI, 2009, p. 5).

Zanovello (2011) destaca que o consumidor é o árbitro da qualidade. Assim, em muitos casos são os consumidores que decidirão os rumos que a instituição irá tomar e quais adaptações ou inovações serão realizadas de modo com que venham satisfazer as exigências desse cliente. Isso quando aplicado em instituições de saúde incorpora conceitos que podem encantar seus clientes. 
A hotelaria adaptada à instituição de saúde torna-se fundamental nesse processo da busca pela qualidade, visando dentro dos serviços desenvolvidos, o bem estar, o conforto e a segurança do paciente. Assim, quando incluída no modelo de gestão, a hotelaria hospitalar pode interferir na hospitalidade e nas relações entre as pessoas envolvidas no contexto hospitalar. Para Boeger (2009), o caminho a ser buscado deve ser agregando a hospitalidade vinda da hotelaria, que tem o cliente como foco de qualquer organização prestadora de serviços, como parâmetro da qualidade.

Assim, a qualidade de um serviço hospitalar pode ser mais facilmente percebida pelo paciente quando a organização tem como objetivo desenvolver seus serviços, visando satisfazer suas necessidades e superar suas expectativas. Ao abordar qualidade é necessário destacar sobre a expectativa do paciente com relação aos serviços recebidos.

No caso em análise, sobre a expectativa dos usuários sobre o sistema único de saúde. Boeger (2011) afirma que por se tratar de conceitos subjetivos dependem da percepção do consumidor e das circunstâncias em que são oferecidos. Isso também está diretamente ligado com experiências passadas de cada individuo em situações semelhantes, assim como sua expectativa diante dessa situação. Em se tratando de serviços de saúde pública, a qualidade do atendimento muitas vezes é alvo de crítica por parte dos usuários, como mencionam Vaitsman e Andrade (2005) onde o simples fato de o paciente ser atendido já pode produzir satisfação, pois as pessoas não têm muita expectativa em relação aos atendimentos do sistema público de saúde.

Em muitos hospitais, a demora pelo atendimento devido filas, a falta de estrutura, aparelhos e profissionais ou o tempo em que é marcado um exame ou consulta com especialista são razões pelas quais as expectativas dos usuários se tornam baixas, e quando problemas como esses são reais, geram a insatisfação desses usuários.

Ressalta-se com isso, a importância da interatividade entre todos os atores envolvidos na saúde pública, instituindo uma cultura de humanização que resulte na percepção do usuário sobre a qualidade do atendimento recebido, superando suas expectativas. 


\section{HOSPITALIDADE EM AMBIENTE HOSPITALAR}

O termo hospitalidade se refere ao gesto de acolher (receber) alguém, tanto em casa quanto em outros locais. A palavra latina hospitalitas (hospitalidade), significa o ato de oferecer bom tratamento a quem se dá ou a quem recebe hospedagem (CÂNDIDO; VIEIRA, 2003).

Para Boeger (2008, p. 54), hospitalidade "é o ato ou o efeito de hospedar, é a qualidade do hospedeiro, ou ainda, bom acolhimento, liberalidade, amabilidade e afabilidade no modo de receber os outros". Ainda, Godoi (2004) define-a como o ato de receber bem ou acolher o visitante, familiar ou um amigo e até mesmo o desconhecido, não importando os interesses envolvidos.

Autores como Camargo (2004), caracterizam a hospitalidade em três esferas: doméstica (privada), pública (social) ou comercial. Quanto a isso, Boeger (2009) destaca que hospitais que cobram por seus serviços (inclusive um hospital público), ao oferecer os serviços tanto assistenciais, quanto de apoio (hoteleiro), estão praticando a hospitalidade comercial, pois há nesse caso a remuneração. Porém, quanto à relação interna, entre os profissionais e os pacientes, pratica-se também a hospitalidade social, sem que haja nenhuma reciprocidade por parte do paciente que recebe o atendimento.

Taraboulsi (2009) destaca que a hospitalidade está se tornando um parâmetro importante para a mensuração da qualidade, tanto de produtos, quanto dos serviços, incluindo nesse contexto a hotelaria, que oferece e disponibiliza hospedagem, conforto, segurança, alimentação, lazer e demais serviços inerentes à atividade de receber o cliente da melhor maneira possível, sendo "a hotelaria a arte de receber e de acolher, porque implica hospitalidade" (TARABOULSI, 2009, p. 156).

Segundo Serson (1999), os conceitos de bem receber e acolher, não devem ser aplicados somente em hotéis e meios de hospedagem relacionados ao turismo, mas inclusive em hospitais e casas de repouso. Para o autor, "o fato desse tipo de estabelecimento ser ou não hospitaleiro acaba por influenciar diretamente, por exemplo, no tempo médico de recuperação de um paciente internado" (SERSON, 1999, p. 9). Quanto a isso, Godoi (2004) destaca que a hospitalidade, é fundamental dentro do ambiente hospitalar, pois está vinculada ao processo de internação para a melhora do 
paciente, levando, consequentemente, à satisfação dos familiares e amigos, se tornando com isso um diferencial na prestação de serviços do hospital.

A hospitalidade presente em hospitais pode ser manifestada através da hotelaria hospitalar, por meio do aconchego no ambiente físico, na humanização dos serviços médicos - hospitalares e na espontaneidade das atitudes das pessoas (TARABOULSI, 2009). Com isso, ela deve ser vista com bons olhos pelos gestores hospitalares e pelos demais colaboradores, visto que além de uma boa estrutura e equipamentos, também é fundamental que o atendimento, o serviço prestado e a humanização pessoal por parte dos funcionários estejam inseridos na cultura da instituição.

São pequenos gestos, vindos de profissionais que estão envolvidos no tratamento, ou daqueles que prestam serviços de apoio dentro da instituição, que podem fazer a diferença durante a permanência do paciente no hospital. Porém, diferentemente dos clientes, que por vontade própria se hospedam em hotéis, os clientes de saúde muitas vezes não possuem essa opção de escolha. Sendo assim, é fundamental distinguir as questões emocionais de um paciente que está internado no hospital, das do cliente do hotel.

Essas questões emocionais também irão influenciar quanto à percepção do paciente em relação ao serviço desenvolvido pelo hospital. Mensurar a qualidade de um serviço hoteleiro, onde o hóspede espera pela hospitalidade, bom atendimento, conforto, um ambiente limpo, organizado e boa alimentação se torna diferente em um ambiente hospitalar, onde o paciente espera primordialmente por um tratamento clínico adequado, com profissionais competentes. Isso não caracteriza que o paciente, enquanto permanece internado, não possui expectativas em relação aos serviços desenvolvidos pelo hospital e, sendo assim, Pimenta (2006, p. 23) afirma que: “atender as expectativas não é necessariamente difícil, mas a complexidade e subjetividade envolvidas acabam por conferir delicadeza à situação". Ou seja, alguns resultados de satisfação irão depender do estado emocional, psicológico e físico em que esse paciente se encontra, porém não impossibilita-os de serem mensurados.

Nesse sentido, os serviços de apoio hospitalar surgem visando a necessidade do acolhimento digno a esse paciente enquanto espera pelo devido tratamento. Com isso, percebe-se quão importante é que todos os profissionais da instituição e todos os setores estejam envolvidos harmoniosamente no intuito de oferecer uma estada menos 
exaustiva ao paciente, agregando os atributos da hospitalidade às práticas diárias de atendimento e serviços prestados.

Oferecer um serviço de qualidade, visando a hospitalidade no atendimento e compreendendo o quanto esses conceitos, quando aplicados na prática dos serviços de saúde, acabam resultando em uma melhor comodidade e bem estar do paciente.

Taraboulsi (2009), afirma que no contexto global atual, quando os limites para a consecução da produtividade por meio da tecnologia, incluindo equipamentos e conhecimento técnico-científico já são atingidos, só há uma coisa a se fazer para melhorar e manter-se no mercado tão competitivo: investimento na humanização hospitalar.

\section{SAC - SERVIÇO DE ATENDIMENTO AO CLIENTE}

O Serviço de Atendimento ao Cliente (SAC) é uma das ferramentas que possibilita a empresa receber o feedback dos seus clientes quanto a possíveis eventos, na compra e no consumo de seus produtos.

O SAC é um elemento estratégico para as empresas, funcionando como um radar, captando assim informações do mercado e complementando-se por intermédio de pesquisas. Funciona também como agente de mudanças, provocando mudanças internas na organização, e como auditor quando atua no controle de serviços. Sob o aspecto Tático-Operacional, o SAC atua de forma a ser solucionador de reclamações, informativo e essencial para a imagem da empresa junto ao consumidor. (ZÜLZKE, 1997, p. 3)

Portanto, o SAC se caracteriza como um retorno que a empresa ou instituição, pública ou privada, independente do serviço prestado, recebe de seus clientes, sendo um canal de comunicação entre consumidor e empresa. Por este fato, afirmam Cruz et al (2005, p. 1359) que "são de extrema importância às indagações, reclamações, sugestões e desejos dos clientes, pois estes conhecem melhor que ninguém as suas próprias necessidades e, portanto podem decidir sobre quais produtos ou serviços adquirir." Além disso, a empresa pode revisar seus produtos e serviços com base nesse retorno do consumidor, adequando-o de acordo com o seu público alvo.

No entanto, há diversas maneiras para detectar a percepção do cliente diante do serviço prestado, alguns instrumentos mais diretos, outros mais indiretos, formais ou 
informais (CRUZ et al., 2005). A empresa deve se adequar a um melhor meio de comunicação com o cliente, que seja mais viável, de acordo com a disponibilidade de tempo, número de funcionários para desempenhar esse serviço, preço, entre outros fatores, de maneira que a estratégia utilizada obtenha maior número de respostas.

Esses instrumentos de pesquisa que caracterizam o SAC devem estar disponíveis aos clientes com vista ao desenvolvimento do marketing da empresa, assim, "ao mesmo tempo que oferece aos clientes um espaço para sua opinião (positiva ou negativa), é considerado pelas empresas que buscam o melhor atendimento como um canal importante para sua estratégia mercadológica" (PYLORIDIS et al., 2003, p. 3), havendo a partir das respostas dos consumidores, um posicionamento da empresa tanto para solucionar quaisquer problemas em relação a insatisfação dos clientes, quanto para se manter competitiva no mercado quando há satisfação ao comprar um produto ou serviço.

É importante que haja a comunicação de forma mais direta com o cliente. Castelli (2006) discorre sobre o instrumento utilizado pela hotelaria para avaliar o desempenho da empresa sob ótica do cliente, onde permite-se identificar os atributos da qualidade julgados por eles fundamentais e coletar a opinião desses clientes em relação a sua satisfação após o consumo. Aponta a importância de abordar em pesquisa com os clientes (SAC), a qualidade de todos os serviços ofertados pelo hotel, bem como todos os setores que são frequentados pelos clientes, e o grau de importância de cada item.

O autor afirma que "o ponto de partida para a elaboração de tais questionários deve ser os clientes. Pode-se, inclusive perguntar a eles que questões gostariam que fossem feitas para se poder avaliar determinado aspecto do serviço que eles almejariam encontrar" (CASTELLI, 2006, p. 126). Com isso, os questionários desenvolvidos para obtenção de um feedback por parte dos clientes mediante serviço prestado deve ser articulado com a realidade de cada empresa e deve ser maleável, de modo que se mantenha a visão da melhoria contínua e atinja ou, de preferência, supere as expectativas dos consumidores.

Portanto, o SAC se torna um controle de qualidade da empresa que retêm as informações dos clientes, com isso é fundamental que qualquer empresa ofereça ao cliente um canal de comunicação como um meio de conhecer suas expectativas e desejos e para obter um retorno da sua satisfação, ou insatisfação após o consumo, 
demonstrando a preocupação no atendimento ao cliente de melhor satisfazer suas necessidades, de reparar possíveis contratempos ocorridos e de inovar em produtos e serviços que fidelizem o cliente e mantenha a empresa competitiva no mercado, sendo o SAC uma dessas ferramentas de comunicação e relacionamento com o cliente.

Considerando a importância do SAC para obtenção de um retorno do cliente à empresa com foco em suas necessidades e expectativas, esse serviço de atendimento ao cliente começa a se difundir também na área médico-hospitalar. O cliente nesse caso é aquele paciente que está sendo atendido por um breve período, enquanto aguarda por um exame, aqueles que permanecem internados no hospital e até mesmo os acompanhantes, pois também utilizarão alguns dos serviços disponibilizados pela instituição. De acordo com Zanovello (2011, p. 82), medir qualidade e quantidade nos serviços de saúde:

[...] é imprescindível para planejamento, organização, coordenação/ direção e avaliação/ controle das atividades desenvolvidas, sendo alvo dessa medição os resultados, os processos e a estrutura necessária ou utilizada, bem como as influências e repercussões promovidas no meio ambiente.

Pois, assim como o cliente para a empresa, o paciente em instituição hospitalar também possui expectativas sobre os serviços desenvolvidos por um hospital, sendo este público ou privado. Portanto, o SAC, quando desenvolvido na instituição de saúde, deve ser adequado a esses serviços prestados pelo hospital, buscando atingir os seus diversos setores tanto os assistenciais, como os de apoio.

Ressalta-se que o SAC não é responsável por tomar providências como forma de solucionar os problemas e reparar as falhas apontadas por parte dos pacientes e acompanhantes, mas ele se caracteriza como um meio de comunicação e relacionamento entre o paciente e acompanhante com o hospital, bem como, com todos os setores envolvidos na prestação de serviço a esses usuários. Assim, o SAC mantém a equipe de profissionais, disponíveis para prestar quaisquer esclarecimentos sobre as circunstâncias que geraram tais reclamações, repassá-las aos responsáveis e realizar o feedback ao reclamante. 


\section{HOTELARIA HOSPITALAR NA PERCEPÇÃO DOS PACIENTES ATENDIDOS}

Considerando que a abordagem dos serviços de hotelaria está mais intrinsecamente vinculada ao paciente internado são apresentados aqui a análise dos setores de clínica médica e cirúrgica realizada no hospital em estudo.

Nos internamentos, há questões destinadas aos serviços desenvolvidos pela hotelaria hospitalar, quanto ao atendimento da copa/cozinha, abordando a educação e respeito dos profissionais, sabor, temperatura e aparência da refeição; à rouparia, quanto à limpeza e manutenção e sobre qualidade das roupas de cama e banho. Ainda, há uma questão relacionada ao serviço de quarto sobre a educação e respeito dos profissionais e limpeza das enfermarias. Além disso, são abordadas questões que correspondem à segurança e confiança do paciente durante o tempo em que ficou acamado e/ou durante a cirurgia e também os espaços para elogios, sugestões ou reclamações.

Para finalizar, o paciente pode responder se o atendimento superou ou não as suas expectativas e o que tornaria melhor o atendimento, ambas com espaços para sugestões, elogios e reclamações.

Com relação aos serviços de copa e cozinha a estrutura do setor de nutrição e dietética contava com duas nutricionistas, sendo uma nutricionista clínica e uma responsável pela produção de alimentos. Além disso, a cozinha do hospital possuía um total de 36 colaboradores no preparo dos alimentos, tanto dos pacientes quanto dos funcionários e 7 copeiras responsáveis por servir as refeições. Todos os servidores, tanto cozinheiras quanto copeiras, cumpriam uma escala de trabalho de 12 por 36 horas.

Para o fornecimento das refeições, diariamente duas servidoras levavam em todos os quartos, para pacientes e acompanhantes, cinco refeições: o café da manhã, almoço, lanche da tarde, jantar e ceia, sendo assim, o contato que os pacientes tinham com os responsáveis pela copa e cozinha do hospital acontecia geralmente no momento em que ocorria a distribuição das refeições no quarto do paciente. Na avaliação sobre respeito e educação dos copeiros, verificou-se que 55 entrevistados na clínica médica e $81 \%$ da clínica cirúrgica afirmaram que esse quesito foi ótimo, respectivamente 85 pessoas e $11 \%$ responderam bom, regular ou ruim não tiveram respostas e 85 entrevistados e $6 \%$ das pessoas não avaliaram este quesito. 
As refeições eram servidas em pratos térmicos com divisórias descartáveis com espaço destinado a cada item. O horário do café da manhã ocorria diariamente à partir das 8:00 horas, o almoço era servido às 11:00 horas, lanche às 15:00 horas, jantar às 18:00 horas e também era servida a ceia às 21:00 horas, esta última era uma refeição mais leve. Em relação ao sabor da refeição 47 entrevistados na clínica médica e 57\% na cirúrgica responderam que estava ótimo, 12 pacientes e $32 \%$ responderam que estava bom, 2 entrevistados e $2 \%$ avaliaram o sabor da refeição como regular, nenhuma pessoa respondeu ruim e 39 pessoas e $9 \%$ não avaliou.

O requisito sobre o sabor da refeição é uma das questões mais relativas da análise, pois cada paciente irá julgá-lo de uma maneira diferente, dependendo dos seus hábitos alimentares, antes do internamento. Além disso, no internamento, devido os processos clínicos necessários para o tratamento, o paciente muitas vezes está com o seu paladar alterado pelo uso de medicamentos, podendo comprometer sua percepção em relação à alimentação fornecida pelo hospital.

Sobre a temperatura da refeição, na clínica médica, 43 pessoas responderam ótimo, 11 bom, 3 respondeu regular, 8 não avaliou e nenhuma pessoa respondeu ruim. $\mathrm{Na}$ análise da clínica cirúrgica teve-se que 58\% dos entrevistados respondeu ótimo, 32\% respondeu bom, $2 \%$ respondeu regular, nenhuma pessoa considerou ruim e $8 \%$ das pessoas não avaliaram a questão sobre a temperatura da refeição.

Quando questionados sobre a aparência da refeição, 47 dos pacientes da clínica médica responderam ótimo para essa questão, 13 bom, nenhuma pessoa regular ou ruim e 5 não respondeu. Já na clinica cirúrgica, $64 \%$ das pessoas responderam ótimo, $24 \%$ respondeu bom, $1 \%$ respondeu regular, nenhuma pessoa respondeu ruim e $11 \%$ das pessoas não avaliaram sobre a aparência da refeição.

Outro departamento coordenado pela Hotelaria é a rouparia. Na rouparia ocorriam os processos de coleta, pesagem da roupa limpa e suja e distribuição, porém os processos de lavagem e secagem desse enxoval aconteciam por meio de uma empresa terceirizada.

Portanto o hospital possuía a área limpa, cujos responsáveis recebiam a roupa diariamente da lavanderia, separavam todo o enxoval, armazenavam e distribuíam a roupa necessária para suprir todos os setores do hospital. Já na área suja, ocorria o 
recolhimento dessa roupa já utilizada em todos os setores que aguardava, também diariamente, que a empresa terceirizada realizasse a coleta.

Além disso, todo enxoval que retornava lavado dessa empresa passava por um processo de análise, havendo medidas específicas quando este estivesse danificado ou manchado. A rouparia contava com um total de 6 servidores, sendo 2 na área suja que realizavam a coleta da roupa utilizada em todas as unidades hospitalares e 4 servidores na área limpa, todos trabalhando em escala de 12 por 36 horas. Todo o enxoval do hospital inventariado, tendo um controle mensal da quantidade de roupa enviada para os setores, bem como a quantidade lavada e o seu retorno. A troca diária das roupas de cama ficava sob responsabilidade da equipe de enfermagem. Assim, cada andar possuía um espaço destinado para armazenagem do enxoval levado pelo servidor da rouparia e o colaborador que realizava a troca dos enxovais retirando da rouparia do andar a quantidade a ser utilizada em cada leito.

Ainda sobre a rouparia, deve-se levar em consideração a então recente inauguração do hospital, possibilitando com isso, que os enxovais disponíveis aos pacientes que ficavam internados, bem como toda sua infraestrutura, estivessem no prazo de vida útil de cada peça, já que se tratava da qualidade do enxoval utilizado. Além disso, a equipe administrativa tinha uma constante preocupação com os descritivos do enxoval a ser comprado por licitação o que garantia a qualidade das peças e a maior durabilidade.

As duas servidoras responsáveis pela costura realizavam os serviços de reparos dos enxovais danificados e a confecção de novos enxovais a serem utilizados.

Sobre as avaliações da rouparia nos quesitos limpeza e manutenção da roupa de cama e banho das clínicas analisadas, foram obtidos os seguintes resultados: entre aqueles que foram questionados sobre esse aspecto do serviço da rouparia, na clínica médica e cirúrgica respectivamente, 60 entrevistados e $82 \%$ das respostas foram ótimo para a limpeza e manutenção das roupas de cama e banho, o quesito bom foi avaliado em 4 pessoas na clínica médica e 14\% como bom. A avaliação regular foi apontada apenas na clínica cirúrgica com percentual de 1\%, nenhuma pessoa respondeu ruim em ambas as clínicas 2 não respondeu essa pergunta.

Outro parâmetro analisado foi a qualidade das roupas de cama e banho disponibilizadas durante o internamento, nessa questão, nas clínicas médica e cirúrgica, 
52 pessoas e $74 \%$ responderam ótimo, 9 pacientes e $18 \%$ responderam bom, na clínica médica nenhuma pessoa respondeu regular, já na cirúrgica $2 \%$ respondeu regular, em ambas as clínicas nenhuma pessoa classificou como ruim e 4 não avaliou sobre a qualidade dos enxovais.

Sobre a limpeza das instalações, o hospital possuía uma equipe de 36 servidores na higienização responsáveis pela limpeza das instalações do hospital que trabalhavam em escala de 12 por 36 horas e 10 funcionários de uma empresa terceirizada que trabalhavam 8 horas diárias. Todos os colaboradores realizavam suas funções diárias de higienização com respaldo de um enfermeiro, responsável técnico do setor e de acordo com as normas estabelecidas pela Agencia Nacional de Vigilância Sanitária - ANVISA, no intuito de amenizar os riscos de contágios e contaminações durante esses procedimentos. Para tanto, todo colaborador que iniciava suas atividades no hospital passava por um processo de capacitação e treinamento de acordo com os procedimentos elaborados pela Seção de Hotelaria Hospitalar.

Nas clínicas analisadas, em torno de $75 \%$ das pessoas responderam ótimo, 7 avaliou a limpeza como bom na clínica médica, enquanto na cirúrgica a limpeza foi considerada como boa para $17 \%$ dos entrevistados, nenhuma pessoa respondeu regular e ruim na clínica médica e 1\% avaliou como regular a limpeza da clínica cirúrgica e 9 das pessoas não responderam este item da médica quanto da cirúrgica $8 \%$ não avaliou esse quesito.

Ainda sobre a limpeza das áreas do hospital, na clínica médica havia também duas questões referentes ao serviço de quarto abordando sobre a educação e respeito dos profissionais e sobre a limpeza das enfermarias. Quanto a esses dois itens, observou-se que $100 \%$ das pessoas abordadas responderam que a educação e respeito dos profissionais no serviço de quarto estavam ótimos. Quando um paciente está internado, ele tem maior contato com a equipe de higienização que realiza todo o procedimento de limpeza nos quartos e com a equipe de enfermagem que realiza as trocas de roupas de cama de pacientes e acompanhantes, pois muitas vezes o paciente não pode se retirar do quarto onde está para que as limpezas de rotina sejam realizadas, por isso é fundamental que o profissional conduza suas atividades de forma que não venha atrapalhar o descanso do paciente e trate-o da melhor maneira possível. 
Essa questão é notada quando abordados sobre a educação dos profissionais no serviço de quarto, os responsáveis pela higienização e troca de enxovais, comprovou-se que todos os entrevistados definiram esse quesito como ótimo, alegando que havia de fato respeito e educação por parte desses profissionais. Sobre a limpeza das enfermarias, considerando-se a soma dos dados das duas clínicas, obteve-se o total de respostas, que: 89\% respondeu ótimo, 6\% respondeu bom, 5\% não avaliou e nenhuma pessoa respondeu regular ou ruim.

Nas questões de ordem subjetiva, onde os pacientes poderiam dar sua opinião, fazer reclamações e sugestões sobre todos os serviços do hospital, tanto nos procedimentos clínicos quanto dos serviços de apoio, foi possível constatar na clínica médica os seguintes dados: das 65 pessoas que responderam as questões avaliativas sobre a clínica médica, 61 respondeu que os serviços em geral atenderam suas expectativas, 2 das pessoas disseram que não atenderam suas expectativas e 2 não avaliou. Nas respostas positivas, observou-se que a maioria elogiou o bom atendimento, educação, atenção e profissionalismo de toda equipe.

Das pessoas que avaliaram negativamente, uma das duas respostas negativas nessa questão teve resposta: "porque não tinha nenhuma expectativa" e a outra avaliação negativa não deixou sua opinião por escrito.

Na clínica cirúrgica, nas questões de ordem subjetiva, observou-se que dos 377 pacientes que responderam as avaliações do SAC referentes aos serviços do setor, no período avaliado, 94\% das respostas foram que os serviços atenderam as suas expectativas, $3 \%$ respondeu que não atenderam suas expectativas e 3\% das pessoas não avaliaram essa questão.

Dentre as respostas negativas, de um total de 11 respostas que representam os $3 \%$ apresentados, apenas dois pacientes deixaram seus comentários relatando o porquê de suas expectativas não serem atendidas. Uma das respostas foi referente ao tempo de espera pela cirurgia, em que o paciente declarou que deu entrada no hospital no dia 5 e a cirurgia foi realizada somente no dia 18 do mesmo mês. Infere-se que nestes casos questões clínicas do paciente interferem na programação inicial, muitas vezes gerando intercorrências também em relação à expectativa dos pacientes.

Em outra resposta, a paciente relatou seu desejo de que fosse realizada uma cirurgia específica na retirada de um ovário policístico. Porém, vale ressaltar, a partir da 
opinião exposta pela paciente, a possibilidade ou não da realização de tal cirurgia. Em muitos casos, o cliente (paciente) não tem suas expectativas atingidas pela impossibilidade do procedimento por ele esperado, mas isso irá depender de diversos fatores, sendo um deles a alternativa de outro tratamento clínico que seja mais eficiente e adequado para o problema apresentado. O risco de outras complicações cirúrgicas são muitas vezes, fatores que impedem um procedimento clínico, por mais que, o paciente o almeje. Estas duas colocações são comprovações de que na hotelaria hospitalar muitos outros fatores estão relacionados na expectativa do paciente, e que, todos estão interligados ao que ele espera receber dos serviços da instituição, inferindo em sua análise sobre os serviços de apoio.

Nas respostas positivas quanto às expectativas dos pacientes, observou-se que, assim como na clínica médica, na clínica cirúrgica as respostas foram referentes ao bom atendimento por parte dos profissionais. Destacaram-se também, 3 comentários mencionando que o atendimento do hospital se igualava ao de um hospital particular; 11 respostas destacaram que os serviços prestados foram além das expectativas que os pacientes e/ou acompanhantes tinham antes de iniciar o processo de internamento no hospital - um deles declarando que não esperava por um bom atendimento e se surpreendeu com o ótimo atendimento e carinho de todos, além de outras respostas sobre a eficiência, organização e limpeza do ambiente.

A última questão abordada nos questionários do SAC aplicados na clínica médica e cirúrgica foi em relação à melhoria do atendimento. Quando questionados com a pergunta: "Na sua opinião, o que tornaria melhor o nosso atendimento?”, na clínica médica, das 65 pessoas questionadas, algumas expressaram sua opinião abordando temas relacionados à quantidade de profissionais, sendo 9 respostas referentes ao aumento do efetivo no quadro de funcionários; 9 pessoas declararam que o atendimento e os serviços do hospital estavam excelentes da maneira que vinham sendo executados. Houve também respostas referentes ao horário da visita, que poderia ser maior; 1 resposta foi sobre a melhora da temperatura do chuveiro no quarto e uma pessoa relatou sua opinião sobre a implantação de uma ala de hospedagem para acompanhantes da UTI.

Na clínica cirúrgica das 377 pessoas que responderam os questionários do SAC analisado, nessa mesma questão sobre o que tornaria melhor o atendimento do hospital, 
também foi observada a opinião daqueles que responderam sobre a contratação de mais profissionais, particularmente médicos especialistas, $1,8 \%$ pessoas responderam que o hospital necessitava de mais funcionários; 7,4\% pessoas declararam que estavam satisfeitas com o atendimento; $1,8 \%$ pessoas opinaram sobre a importância de ter uma lanchonete no hospital ou nas proximidades, para visitantes e acompanhantes; outras $0,8 \%$ das respostas foram referentes ao funcionamento do hospital, alegando que deveria funcionar na sua totalidade; $0,8 \%$ das respostas foram destinadas à manutenção do hospital, especialmente sobre as TVs; 3 destacaram que deveria haver melhora na agilidade do atendimento; 1 relatou que o quarto estava sujo quando deu entrada no hospital; 1 pessoa reclamou sobre o atendimento da recepção; 1 pessoa comentou sobre o café da manhã e 1 resposta foi referente a possibilidade de ter acompanhantes nos quartos.

Realizando o emparelhamento das informações coletadas (LAVILLE; DIONE, 1999) comprova-se que a hotelaria do hospital estava desempenhando seus serviços priorizando o paciente e acompanhante, pois são eles, juntamente com os clientes internos (demais servidores) que irão receber pelos serviços de rouparia, alimentação e limpeza das áreas do hospital. Portanto, a hotelaria objetiva oferecer a qualidade nos serviços que por ela são administrados, garantindo que as necessidades implícitas dos pacientes sejam atendidas, pois além da oferta de tratamento clínico e exames, trata-se de desejos e expectativas que os pacientes têm diante de todos os serviços do hospital.

De acordo com aqueles que expuseram sua opinião sobre o hospital, grande parte alegou que por se tratar de um hospital totalmente público, apresentava características de serviços tão bons quanto hospitais particulares. Observando-se com isso que além de recursos financeiros, o desenvolvimento eficiente de um hospital irá depender da visão de gestão que é estabelecida. Essa afirmação está relacionada com o conceito apresentado por Boeger (2008) onde afirma que muitos hospitais privados possuem uma visão errônea sobre a hotelaria hospitalar e acabam resistindo em centralizar os serviços de apoio hospitalar, os quais deveriam ser coordenados por um profissional de hotelaria e não o fazem por falta de compreensão na semelhança entre hotéis e hospitais.

Quando o hospital oferece serviços de qualidade, os pacientes retribuem com elogios e respostas positivas. Os resultados da pesquisa do SAC da instituição em 
estudo demonstraram que os pacientes puderam expor sobre suas expectativas, descrevendo os serviços desenvolvidos pelo hospital. Comprovou-se conforme a visão de uma paciente que respondeu os formulários de pesquisa os serviços da hotelaria estavam sendo de excelência.

Ainda, é possível afirmar que a percepção da qualidade é formada no mesmo instante em que o serviço é desenvolvido, portanto, muitos dos resultados são satisfatórios em função do atendimento e acolhimento por parte dos profissionais responsáveis no ato do serviço prestado. Isso ocorre no momento da verdade (CASTELLI, 2006), quando a copeira leva a refeição até o quarto, ou quando a servidora responsável pela limpeza e serviço de quarto realiza suas funções de maneira que perceba a presença do paciente, cumprimentando-o e tratando-o da melhor forma possível, ou ainda percebendo aquele enxoval que está sempre limpo, organizado e disponível para uso.

Por isso, a hotelaria hospitalar também prioriza a capacitação dos servidores, levando-os à compreensão da importância da qualidade no atendimento e nos serviços prestados. Além disso, o setor está envolvido nas questões sobre a humanização hospitalar, participando ativamente em eventos e palestras sobre o referido tema.

A importância de conhecer o paciente, de saber ouvir quando há reclamações e resolver qualquer problema apresentado, demonstra a preocupação da instituição em oferecer serviços cada vez melhores a seus usuários. É possível relacionar com isso, o conceito descrito anteriormente, em que o próprio cliente é o árbitro da qualidade. É ele quem irá decidir os rumos e as adequações que uma empresa ou instituição irá efetuar para que seus serviços sejam de qualidade, de maneira que venham encantá-los.

\section{CONSIDERAÇÕES FINAIS}

Devido à expansão do estudo e atuação do turismo na atualidade, percebe-se um grande potencial em desenvolvimento, que são os conceitos e serviços desenvolvidos na hotelaria se fazendo presente nas instituições de saúde. Além disso, a similaridade desses dois meios de hospedagem, a hotelaria tradicional e a hotelaria hospitalar, se dá primeiramente a partir da sua evolução histórica, uma vez que hotéis e hospitais 
iniciaram de um mesmo empreendimento e também pelas estruturas funcionais dos dois ambientes, já que ambos hospedam pessoas oferecendo os serviços de limpeza, alimentação, recepção etc.

Para tanto foi possível considerar a funcionalidade dos departamentos que compõem um hotel com os serviços desenvolvidos pelo setor de hotelaria hospitalar nos hospitais, concluindo com isso, que, mesmo respeitando o escopo e as particularidades dos serviços hospitalares, já que são muito mais complexos que na hotelaria, suas características e seus objetivos são semelhantes nos dois ambientes, se levados em conta à preocupação que têm em oferecer aos clientes/pacientes ambientes e serviços de qualidade, tendo-os como foco no desenvolvimento de tal prática. Nesse contexto, observou-se também que estão presentes dentro do hospital analisado conceitos antes oriundos da hotelaria tradicional, como a hospitalidade agora aliada ao conceito de humanização hospitalar.

Uma gestão que entende a importância de relacionar os serviços da hotelaria com os de um hospital já demonstra que busca a melhoria da qualidade em serviços oferecidos pela instituição. Para tanto, é necessário que estejam inseridos na equipe hospitalar, profissionais que dominem a esfera hoteleira e adapte-a as particularidades do hospital.

Percebeu-se que os serviços da hotelaria presentes no hospital em estudo estavam sendo desempenhados de forma eficiente, e contribuindo para uma melhor satisfação dos seus usuários. Com base nos resultados do SAC aplicado no hospital foi possível identificar como os pacientes analisaram esses serviços de apoio e a importância destes serem desempenhados da melhor maneira possível ofertando melhor conforto e comodidade ao paciente enquanto ele permanece internado. São fatores que muitas vezes são vistos como secundários, quando considerado a principal função de um hospital, que em senso comum, é um tratamento adequado ao paciente, mas que também são responsáveis por todo seu funcionamento e quando oferecidos com qualidade aos pacientes, acabam excedendo suas expectativas.

Por isso, uma significativa parcela daqueles que responderam as questões relacionadas aos serviços coordenados pela hotelaria do hospital em estudo, avaliou os requisitos sobre a alimentação, limpeza, serviço de quarto e atendimento dos profissionais como ótimo e bom, algumas pessoas avaliaram como regular e nenhuma 
pessoa definiu algum aspecto do serviço recebido como ruim. Concluindo com isso as afirmações expostas, em que os serviços da hotelaria são fundamentais em todo processo de tratamento dos pacientes e em qualquer momento do internamento, contribuindo para o seu bem estar e comodidade, levando-o à percepção da individualidade no atendimento dentro da instituição.

Ainda, constatou-se a importância de qualquer empresa ou instituição estabelecer um mecanismo que controle e mantenha contato com o cliente, sendo um sistema interno de informatização ou questionários avaliativos sobre o serviço, como o SAC, possibilitando com isso conhecer as preferências, desejos e aversões dos clientes sobre o estabelecimento e serviço recebido.

Com a conclusão desse trabalho, deseja-se que essa área de atuação seja de fato coordenada por profissionais que compreendam a esfera hoteleira inseridos na complexidade e multidisciplinaridade de hospitais e haja continuidade na disposição de "ouvir" o paciente que recebe os serviços do hospital, por meio de mecanismos como o SAC, importante fator para a mensuração da qualidade oferecida em serviços e percebida pelos usuários.

\section{REFERÊNCIAS}

BOEGER, M. Introdução à Hotelaria hospitalar. Hotelaria Hospitalar. Manuais de Especialização. 1. ed. Barueri - SP: Manole, 2011. p. 1-32.

Gestão em Hotelaria Hospitalar. 3. ed. São Paulo: Atlas, 2008.

Hotelaria Hospitalar: Gestão em hospitalidade e humanização. São Paulo: Senac, 2009.

BRANCO, G. M; RIBEIRO, J. L. D.; TINOCO, M. A. C. Determinantes da satisfação e atributos da qualidade em serviços da hotelaria. Lume Repositório Digital UFRGS, São Paulo, SP. v. 20, n. 4, p. 576-588, out./dez., 2010. Disponível em: <http://www.lume.ufrgs.br/handle/10183/30566>. Acesso em: 28/08/2013.

CAMARGO, L. O. L. Hospitalidade. São Paulo: Aleph, 2004.

CANDIDO, I; VIEIRA, E. Gestão de Hotéis: Técnicas, operações e serviços. Caxias do Sul. Educs, 2003. 
CASTELLI. G. Administração Hoteleira. São Paulo: Saraiva, 2006.

CRUZ. A. M. O.; FERNANDES, A. da C.; LEITE, B. H. da F. da C.; SÁ, C. S. de; CRUZ FILHO, N. de O. C. Serviço de atendimento do cliente (SAC): um instrumento de gestão ou uma mera formalidade para cumprir exigências legais? In: ENCONTRO NAC. DE ENGENHARIA DE PRODUÇÃO, 25, 2005, Porto Alegre. Anais eletrônicos. Porto Alegre: ABEPRO - PUCRS, 2005, p. 1358-1365. Disponível em: <http://www.abepro.org.br/biblioteca/ENEGEP2005_Enegep0201_0599.pdf〉. Acesso em: 26 de jul de 2013.

DI DIO. G. S. C. Z; RETTONDINI, O. C; SOUZA, F. G. Hotelaria Hospitalar: Estratégias da diferenciação na busca da vantagem competitiva. In: TRIGO. L. G. G. (org.) Análises regionais e globais do turismo brasileiro. São Paulo: Roca, 2005. Cap. 52 , p. 805-815.

GODOI, A. F. Hotelaria Hospitalar e Humanização no atendimento em hospitais: pensando e fazendo. São Paulo: Ícone, 2004.

LAVILlE, C.; DIONNE, J. A construção do saber: manual de metodologia da pesquisa em ciências humanas. UFMG, 1999

MOLLER, C. O lado humano da qualidade: Maximizando a qualidade dos produtos e serviços através do desenvolvimento das pessoas. São Paulo: Pioneira Thomson Learning, 2002.

PIMENTA, M. A. Gestão de pessoas em turismo: sustentabilidade, qualidade e comunicação. Campinas: Alínea, 2006.

PINTO, R. C. Excelência em serviços: o valor percebido pelo cliente. Revista de Ciências Gerenciais, São Paulo, v. 10, n 12, p. 58-72, 2006. Disponível em: <http://sare.anhanguera.com/index.php/rcger/article/view/66>. Acesso em: 10/09/2013.

PYLORIDIS, K. C.; OLIVEIRA, M. J. da C.; PERANDRÉA, N. G.; GAVIOLI, R. O SAC e a Comunicação Mercadológica. Publicidade, Comunicação e Consumerismo: edição 2003, São Paulo, 2003. Disponível em: <http://www.portcom.intercom.org.br/pdfs/9420ca3b127f1d39cd124b954431fa23.PDF >. Acesso em: 26/07/2013.

RODRIGUES, F. F; LEAL, M. L; HARGREAVES, L. Qualidade em prestação de serviços. Rio de Janeiro: SENAC, 1997.

SERSON, F. Hotelaria: a busca da excelência. São Paulo: Marcos Cobra, 1999.

WADA, E. Quem são os profissionais da Hotelaria Hospitalar?Anais do I - SIHNAE - SIMPÓSIO DE HOTELARIA HOSPITALAR HOSPITAL ISRAELITA ALBERT EINSTEIN. São Paulo, 20, ago. 2011. 
TARABOUlSI, F. A. Administração de Hotelaria Hospitalar. 4. ed. São Paulo: Atlas, 2009.

VAITSMAN, J; ANDRADE, G. R. B. Satisfação e responsividade: formas de medir a qualidade e a humanização da assistência à saúde. Revista Cência \& Saúde Coletiva, Rio de Janeiro, RJ., v. 10, n. 3, p. 599-613, jul./set., 2005. Disponível em: <http://www.scielo.br/scielo.php?pid=s1413-81232005000300017\&script=sci_arttext $>$. Acesso em: 10/09/2013.

ZANOVELLO, A. L. Qualidade aplicada aos serviços da saúde. In: BOEGER, M. (coord). Hotelaria Hospitalar. Manuais de Especialização. 1. ed. Barueri - SP: Manole, 2011. p. 75-86.

ZÜLZKE, M. L. Abrindo a Empresa Para o Consumidor: a importância de um canal de atendimento. 2. ed. Rio de Janeiro: Qualitymark, 1997.

Recebido em: 23-02-2015.

Aprovado em: 25-03-2015. 